Article

\title{
Impact of Electrocautery on Fatigue Life of Spinal Fusion Constructs-An In Vitro Biomechanical Study
}

\author{
Haidara Almansour ${ }^{1}{ }^{(D}$, Robert Sonntag ${ }^{2}{ }^{(D}$, Wojciech Pepke ${ }^{1}$, Thomas Bruckner ${ }^{3}$, \\ Jan Philippe Kretzer ${ }^{2}$ and Michael Akbar ${ }^{1, *}$ \\ 1 Clinic for Orthopedics and Trauma Surgery, Heidelberg University Hospital, 69118 Heidelberg, Germany \\ 2 Laboratory of Biomechanics and Implant Research, Clinic for Orthopedics and Trauma Surgery, Heidelberg \\ University Hospital, 69118 Heidelberg, Germany \\ 3 Institute of Medical Biometry and Informatics, University of Heidelberg, 69118 Heidelberg, Germany \\ * Correspondence: michael.akbar@med.uni-heidelberg.de; Tel.: +49-6221-56-26305 or +49-6221-56-27630; \\ Fax: +49-6221-56-27307
}

Received: 5 July 2019; Accepted: 31 July 2019; Published: 3 August 2019

\begin{abstract}
Instrumentation failure in the context of spine surgery is attributed to cyclic loading leading to formation of fatigue cracks, which later propagate and result in rod fracture. A biomechanical analysis of the potential impact of electrocautery on the fatigue life of spinal implants has not been previously performed. The aim of this study was to assess the fatigue life of titanium (Ti) and cobalt-chrome $(\mathrm{CoCr})$ rod-screw constructs after being treated with electrocautery. Twelve spinal constructs with $\mathrm{CoCr}$ and Ti rods were examined. Specimens were divided into four groups by rod material (Ti and $\mathrm{CoCr}$ ) and application of monopolar electrocautery on the rods' surface (control-group and electrocautery-group). Electrocautery was applied on each rod at three locations, then constructs were cyclically tested. Outcome measures were load-to-failure, total number of cycles-to-failure, and location of rod failure. Ti-rods treated with electrocautery demonstrated a significantly decreased fatigue life compared to non-treated Ti-rods. Intergroup comparison of cycles-to-failure revealed a significant mean decrease of almost $9 \times 10^{5}$ cycles $(p=0.03)$. No CoCr-rods failed in this experiment. Electrocautery application on the surface of Ti-rods significantly reduces their fatigue life. Surgeons should exercise caution when using electrocautery in the vicinity of Ti-rods to mitigate the risk of rod failure.
\end{abstract}

Keywords: electrocautery; titanium alloy; cobalt-chrome alloy; fatigue behavior; biomechanical study

\section{Introduction}

Electrocautery and spinal implants are principal tools in the spine surgeon's armamentarium. These tools are utilized in complex surgeries to treat a multitude of spinal conditions and to ameliorate patients' disabilities [1,2].

Technological advancements in biomechanics and biomaterials have revolutionized the sphere of spinal instrumentation, enabling surgeons to widen the indications for corrective surgery, and broadened the array of surgical techniques. In this context, spinal fusion was first introduced by Hibbs and Peltier to stabilize a spine affected by tuberculosis [3,4]. Albee used the tibia as graft material for spine stabilization [5]. King [6] and Lange [7] attempted internal fixation [1,4]. Harrington [8] introduced an innovative rod distraction system to correct coronal deformity [4], and Cotrel and Dubousset metamorphosed the profession with their segmental instrumentation for simultaneous correction of coronal and sagittal planes, thereby facilitating a three-dimensional (3D) approach to treat a 3D spine deformity [9]. These surgeries demand sophisticated technical aptitude and hence require meticulous preoperative planning. Consequently, one of the major preoperative decisions is choosing the correct deformity-specific, pathology-appropriate, spinal fusion construct [1]. 
Spinal implants must fulfil many criteria to be considered safe and efficient. Qualities such as biocompatibility, osseointegration, high strength, low Young's modulus, high corrosion, and wear resistance are pivotal to implants' long-term performance. Because no current material can fulfil all the clinical and biomedical requirements, material scientists have endeavored to enhance these qualities utilizing many surface modification techniques [10]. These processes include mechanical treatment, sol-gel application, thermal spraying, chemical and electrochemical treatment, micro-arc oxidation, laser surface modification, friction stir processing, and ion application [11,12].

Heating techniques and plasmochemical techniques occupy an important role in the sphere of biomedical engineering and materials science. Heat treatment is utilized to increase the fatigue strength of an alloy and to orchestrate an optimal balance of the material's ductility, machinability, and stability [10]. Plasma implementation is non-toxic because it is free of solvents [13]. Implementing techniques such as plasma assisted microwave chemical vapor deposition, plasma etching, plasma nitriding, and deposition of a-DLC (amorphous diamond-like carbon) layers inoculated with nitrogen and silicon have been shown to have a significant impact on the microstructure and surface characteristics of alloys [13].

Accurate and appropriate surface modification techniques diversify and optimize the clinical use of alloys in surgical fields. However, spine surgeries are overburdened with post-operative complications [2], including implant-related failure and rod fracture (RF) [1]. The overall complication rates of surgical corrections of spine-deformity are reported to be $30 \%$ within two-years after surgery [1418]. An important source of complications remains the intrinsic limitation of the robustness of spinal implants [15,19-24]. In a prospective multicenter assessment of risk factors for early RF following adult spinal deformity (ASD) surgery with one-year follow-up, Smith et al. [16] identified that RF occurred in as many as $9 \%$ of ASD patients, and up to $22 \%$ in patients who underwent pedicle subtraction osteotomy (PSO), a powerful technique for the correction of sagittal spino-pelvic malalignment. In another retrospective study, Smith et al. [23] found that most RF occurred within one year of index surgery.

In the literature to date, several risk factors for RF have been analyzed. They could be patient-related-e.g., higher Body Mass Index (BMI), patient age, history of spine surgery, development of pseudarthrosis, and greater baseline sagittal spinopelvic malalignment (Sagittal Vertical Axis (SVA), Pelvic Tilt (PT), and Pelvic Incidence-Lumbar Lordosis (PI-LL) mismatch), and a greater need for sagittal correction-or implant-related (implant material, or in situ rod contouring in the context of PSO) $[16,21,23,24]$. Notably, the arthroplasty literature provided a clue to an underlying confounder camouflaged behind the subtleties of RF: the thermal damage of electrocautery to the microstructure of implants. Huber et al. [25] were the first to document a case of shaft breakage of a hip endoprosthesis secondary to contact with an electrocautery device. Subsequently, Konrads et al. [26] reported on four similar cases which occurred after revision surgery. These authors argued that the thermal microstructural disruption ensued from an intra-operative electric arc seen post-contact of the electrosurgical electrode with the implant; this could have eventually led to breakage of the implant at the contact point. In addition, Yuan et al. [27] examined 1859 explanted hip implants and concluded that "iatrogenic arc melting" due to electrocautery was responsible for the color changes and corrosion on the surface of the studied implants. Furthermore, via fatigue testing, metallurgic analysis, and electron microscopy, Sonntag et al. [28] delineated a microstructural change in the Ti6A14V base material with high-frequency electrosurgery on hip endoprosthesis, resulting in a decreased load-to-failure when the electrocautery tip was applied to high-load areas of the stem during revision surgery.

Clinically speaking, it is difficult to avoid contact between the electrocautery tip and the implant during spine surgery. Particularly in cases of revision surgery, these electrical arcs could be deemed common.

To the best of our knowledge, this is the first biomechanical study that addresses this topic in spine surgery. In concordance with the American Standard for Testing and Materials, our objective 
was to assess the impact of electrocautery contact on the fatigue life of titanium (Ti) and cobalt-chrome $(\mathrm{CoCr})$ spinal implants.

\section{Materials and Methods}

\subsection{Spinal Fusion Constructs and Vertebrectomy Models}

Twelve unused specimens of $\mathrm{CoCr}$ and Ti implants were included (Expedium Spine, DePuy, Raynham, MA, USA). All rods and pedicle screw constructs had the same diameter $(5 \mathrm{~mm})$ and were cut to a length of $100 \mathrm{~mm}$. Monoaxial pedicle screws (Ti6-Al4-V, $5.5 \mathrm{~mm} \times 7 \mathrm{~mm} \times 30 \mathrm{~mm}$ ) and locking screws (Ti6-Al4-V, $7 \mathrm{~mm}$ ) were used to rigidly couple the rods on the vertebrectomy model according to manufacturer-specific instructions using original instruments. Models were composed of dual Polypoxymethylene (POM) with dimensions as described by the American Standard for Testing and Materials (ASTM) F1717 [29]. This standard provides a uniform approach to conduct fatigue testing on spinal implants. The two blocks comprising each vertebrectomy model simulate two adjacent vertebrae fixed by posterior-instrumentation. The standard distance between the two blocks was $56 \mathrm{~mm}$.

Specimens were divided into four groups by rod material and application of monopolar-electrocautery device on the rods' surface (Table 1).

Table 1. Specimen grouping matrix.

\begin{tabular}{lcc}
\hline Group & Description & Samples \\
\hline Ti-CG & Titanium rods control group (without electrocautery application) & $n=3$ \\
Ti-EG & Titanium electrocautery group & $n=3$ \\
CoCr-CG & Cobalt-Chrome control group (without electrocautery application) & $n=3$ \\
CoCr-EG & Cobalt-chrome electrocautery group & $n=3$ \\
\hline
\end{tabular}

$\mathrm{Ti}=$ titanium; $\mathrm{CoCr}=$ cobalt-chrome; $\mathrm{CG}=$ control group; $\mathrm{EG}=$ electrocautery group.

\subsection{Electrocautery Contact}

Electrocautery application (VIO-300, Erbe Elektromedizin, Tübingen, Germany) was performed by an experienced spine surgeon. Analogous settings used in the operation room of our institution were utilized (mode: swift-coag, 90 Watt, effect: 3, duration: $~ 4$ s). High-frequency monopolar-electrocautery was applied on the surface of each rod at three defined positions (Figure 1). Under these conditions electric light arc was visible in all cases and discoloration of the rod surface was observed.

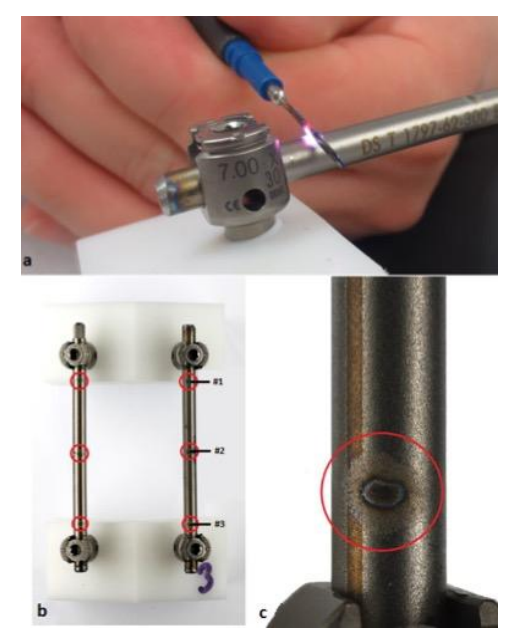

Figure 1. Electrocautery application. (a) Electric light arc, (b) sites, and (c) magnified view of the surface impact post electrocautery application. The first site was approximately $5 \mathrm{~mm}$ from the cephalic pedicle screw (\#1). (\#2 was at the center and \#3 was analogous to \#1 on the other side). 


\subsection{Dynamic Mechanical Testing}

Models were mounted in a servo-hydraulic uniaxial testing apparatus (HCE, Bosch-Rexroth, Lohr a. Main, Germany) under dry conditions such that the rods were aligned in the direction of vertical force application. The upper and lower vertebrae blocks were free to rotate in order to account for any bending of the rods during dynamic testing. A multistep fatigue test was performed at a frequency of $12 \mathrm{~Hz}$ (Figure 2).

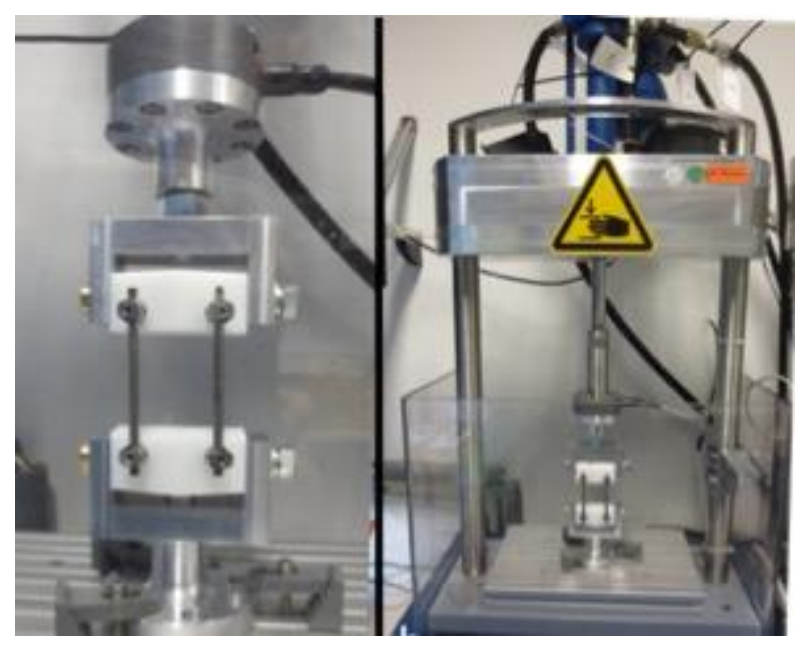

Figure 2. Frontal view of the fatigue testing setup.

Tests started at an initial maximum sinusoidal load of $100 \mathrm{~N}$ (minimal load: $10 \mathrm{~N}$ ). After one million cycles, the maximum load was increased by $50 \mathrm{~N}$, and the load ratio $R$ was kept constant at 0.1 , until construct failure occurred. Based on the total number of steps and cycles completed, the estimated load-to-failure was calculated using this formula:

$$
F_{D}=F_{-1}+50 N \cdot \frac{\mathrm{n}}{1,000,000}
$$

where $\mathrm{F}_{-1}$ is the maximum force of the previous step before fracture, and $\mathrm{n}$ is the number of cycles in the step where the specimen failed.

\subsection{Outcome Measures}

Primary outcomes estimated load-to-failure, total number of cycles to failure, and location of rod failure.

\subsection{Statistical Analysis}

One-way analysis of variance (ANOVA) with post-hoc-test correction of least statistical difference was used to compare continuous values of the outcome measures. All data are presented as mean values \pm standard deviation and $95 \%$ confidence interval. Statistical tests were computed using statistical package (SPSS-v.24, IBM, Armonk, NY, USA). The threshold of statistical significance was set at 0.05 .

\section{Results}

Results of the biomechanical test are summarized in Tables 2 and 3. 
Table 2. Summary of the dynamic biomechanical test results.

\begin{tabular}{|c|c|c|c|c|c|c|}
\hline $\begin{array}{c}\text { Spinal } \\
\text { Construct }\end{array}$ & $\begin{array}{l}\text { Electrocautery } \\
\text { Application }\end{array}$ & $\begin{array}{l}\text { Completed } \\
\text { Load Level }\end{array}$ & $\begin{array}{c}\text { Min/Max } \\
\text { Load at } \\
\text { Failure (N) }\end{array}$ & $\begin{array}{l}\text { No. Cycles } \\
\text { to Failure }\end{array}$ & Failure Site & $\begin{array}{c}\text { Fatigue } \\
\text { Strength (N) }\end{array}$ \\
\hline Ti-CG1 & No & $\# 4$ & $30 / 300$ & $4,473,034$ & Unilateral rod-screw junction & 273.6 \\
\hline Ti-CG2 & No & \#4 & $30 / 300$ & $4,388,472$ & Bilateral rod-screw junction & 269.4 \\
\hline Ti-CG3 & No & $\# 3$ & $25 / 250$ & $3,995,938$ & Unilateral rod-screw junction & 249.8 \\
\hline Ti-EG1 & Yes & \#3 & $25 / 250$ & $3,093,921$ & Bilateral peripheral rod fractures & 204.7 \\
\hline Ti-EG2 & Yes & $\# 3$ & $25 / 250$ & $3,328,583$ & Unilateral peripheral rod fracture * & 216.4 \\
\hline Ti-EG3 & Yes & \#3 & $25 / 250$ & $3,770,073$ & Bilateral central rod fractures & 238.5 \\
\hline CoCr-CG1 & No & \#6 & $40 / 400$ & $6,351,621$ & Bilateral pedicle screws ${ }^{* *}$ & 367.6 \\
\hline CoCr-CG2 & No & \#7 & $40 / 400$ & $7,000,000$ & Bilateral pedicle screws ${ }^{* *}$ & 400 \\
\hline CoCr-CG3 & No & \#7 & $45 / 450$ & $7,183,433$ & Bilateral pedicle screws ${ }^{* *}$ & 409.2 \\
\hline CoCr-EG1 & Yes & \#7 & $45 / 450$ & $7,079,071$ & Bilateral pedicle screws ** & 403.9 \\
\hline CoCr-EG2 & Yes & $\# 7$ & $45 / 450$ & $7,118,378$ & Bilateral pedicle screws ** & 405.9189 \\
\hline CoCr-EG3 & Yes & \#6 & $40 / 400$ & $6,112,167$ & Bilateral pedicle screws ${ }^{* *}$ & 355.60835 \\
\hline
\end{tabular}

CG = Control Group; EG = Electrocautery Group; $\mathrm{N}=$ Newton; $\mathrm{Ti}=$ Titanium; $\mathrm{CoCr}=$ Cobalt-Chrome. ${ }^{*}$ Ti-EG2 fracture site occurred at the level of the locking screws, not at the site of electrocautery application. ${ }^{* *}$ all pedicle screws were made of titanium. No CoCr rods failed in this biomechanical investigation.

Table 3. Summary of load-to-failure and total number of cycles to failure for all tested groups.

\begin{tabular}{|c|c|c|c|c|c|c|}
\hline & Load to Failure $(\mathrm{N})$ * & $95 \%$ CI & $p$ & No. Cycles to Failure * & $95 \% \mathrm{CI}$ & $p$ \\
\hline Ti-CG & $264.3 \pm 12.7$ & [232.7-295.9] & \multirow{2}{*}{$p=0.02$} & $4.3 \times 10^{6} \pm 25 \times 10^{3}$ & {$\left[3.6 \times 10^{6}-4.9 \times 10^{6}\right]$} & \multirow{2}{*}{$p=0.03$} \\
\hline Ti-EG & $219.8 \pm 17.2$ & [177.2-262.5] & & $3.4 \times 10^{6} \pm 34 \times 10^{3}$ & {$\left[2.5 \times 10^{6}-4.2 \times 10^{6}\right]$} & \\
\hline CoCr-CG & $392.2 \pm 21.8$ & [338.1-446.5] & \multirow{2}{*}{$p>0.05$} & $6.8 \times 10^{6} \pm 43 \times 10^{3}$ & {$\left[5.7 \times 10^{6}-7.9 \times 10^{6}\right]$} & \multirow{2}{*}{$p>0.05$} \\
\hline CoCr-EG & $388.5 \pm 28.5$ & [317.7-459.3] & & $6.8 \times 10^{6} \pm 57 \times 10^{3}$ & {$\left[5.3 \times 10^{6}-8.2 \times 10^{6}\right]$} & \\
\hline
\end{tabular}

* Mean \pm standard deviation, $\mathrm{CI}=$ Confidence Interval, $\mathrm{N}=$ Newton, $p$ : Bold denotes statistical significance, $\mathrm{Ti}=$ Titanium, $\mathrm{CoCr}=$ Cobalt-Chrome, $\mathrm{CG}=$ Control Group, $\mathrm{EG}=$ Electrocautery Group.

\subsection{Titanium Control Group (Ti-CG)}

All specimens exhibited fatigue fracture of the rod at the rod-screw junction (Figure 3).

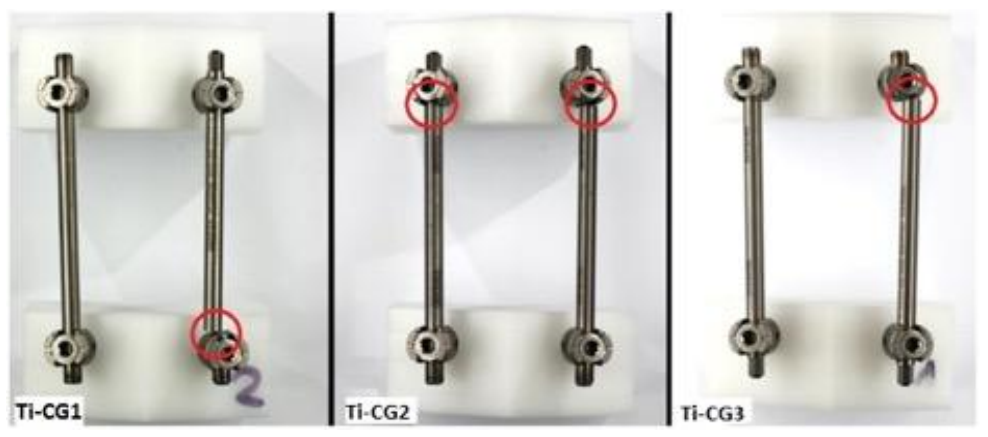

Figure 3. Sites of rod fracture of titanium control group (Ti-CG) post biomechanical testing and fatigue fractures of the rods at the rod-screw junction.

\subsection{Titanium Electrocautery Group (Ti-EG)}

In two specimens (Ti-EG1 and Ti-EG3), failure sites corresponded to the sites of electrocautery application (Figure 4). 


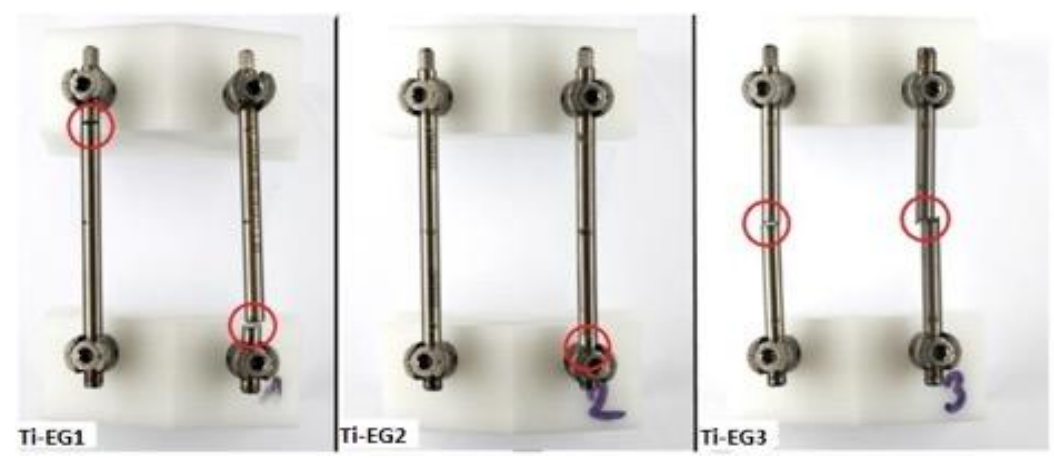

Figure 4. Sites of rod fracture of titanium electrocautery group (Ti-EG) post biomechanical testing.

Ti-EG revealed a significantly lower load-to-failure than Ti-CG (17\% decrease, $p=0.023)$. Intergroup comparison of cycles to failure revealed a significant mean decrease of almost $9 \times 10^{5}$ cycles $(p=0.03)$. (Figure 5).

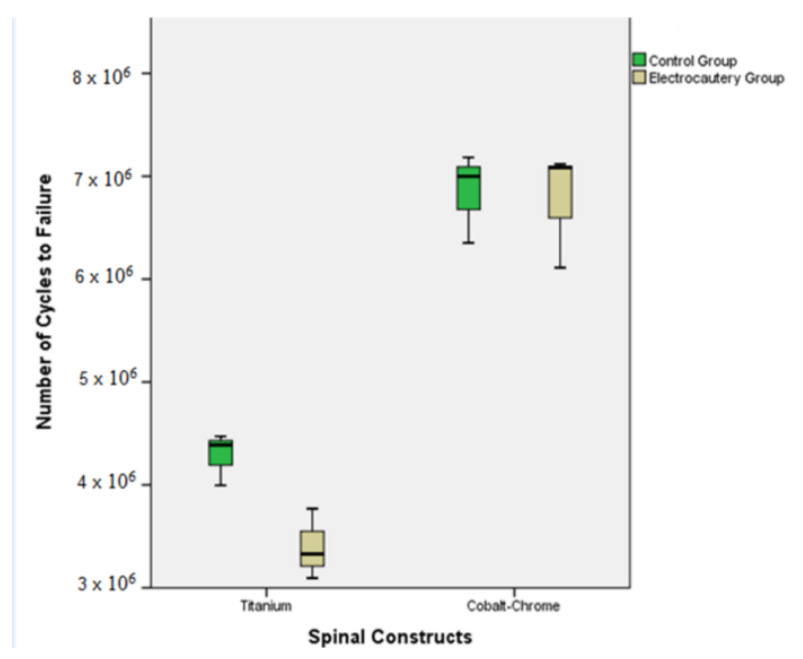

Figure 5. Boxplot representing the mean and $25 \%$ and $75 \%$ interquartile range of the total number of cycles to failure among the four tested groups.

Fatigue failure was confirmed by microscopic analysis of the fractured surface (Figure 6).

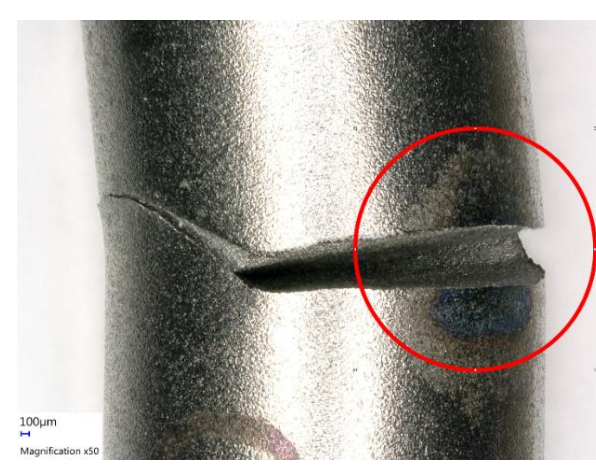

(a)

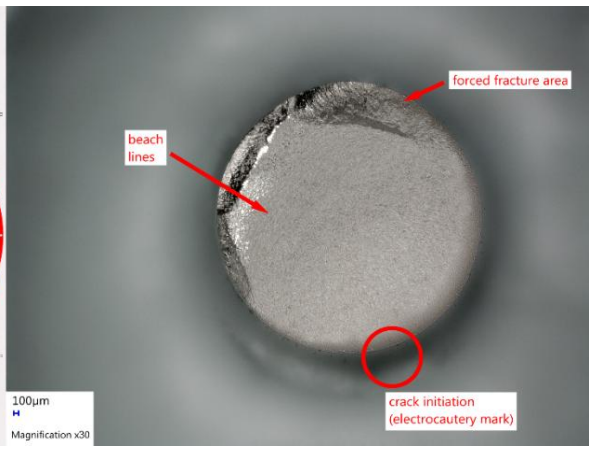

(b)

Figure 6. Microscopic analysis of fractured titanium rod after electrocautery (VHX-5000, Keyence, Osaka, Japan). (a) Post-fracture situation at the electrocautery mark. (b) Fracture surface with typical signs of fatigue fracture (beach lines and forced fracture area). The circle shows the location of crack initiation at the electrocautery mark. 
Notably, Ti-EG2 failed at the rod-screw junction similar to all of the Ti-CG rods.

\subsection{CoCr Control Group (CoCr-CG) and Electrocautery Group (CoCr-EG)}

In all tested constructs, the Ti pedicle screw failed. None of the CoCr-CG or CoCr-EG rods had fractured, exhibiting an increased load-to-failure in comparison to their Ti counterparts.

Intergroup differences were insignificant across all outcome measures. This implies that, in these tested constructs, the pedicle screw proved to be the weakest component under cyclic loading. In all specimens of these two groups, fatigue fracture transpired at the first thread of the titanium pedicle screw (Figures 7 and 8).

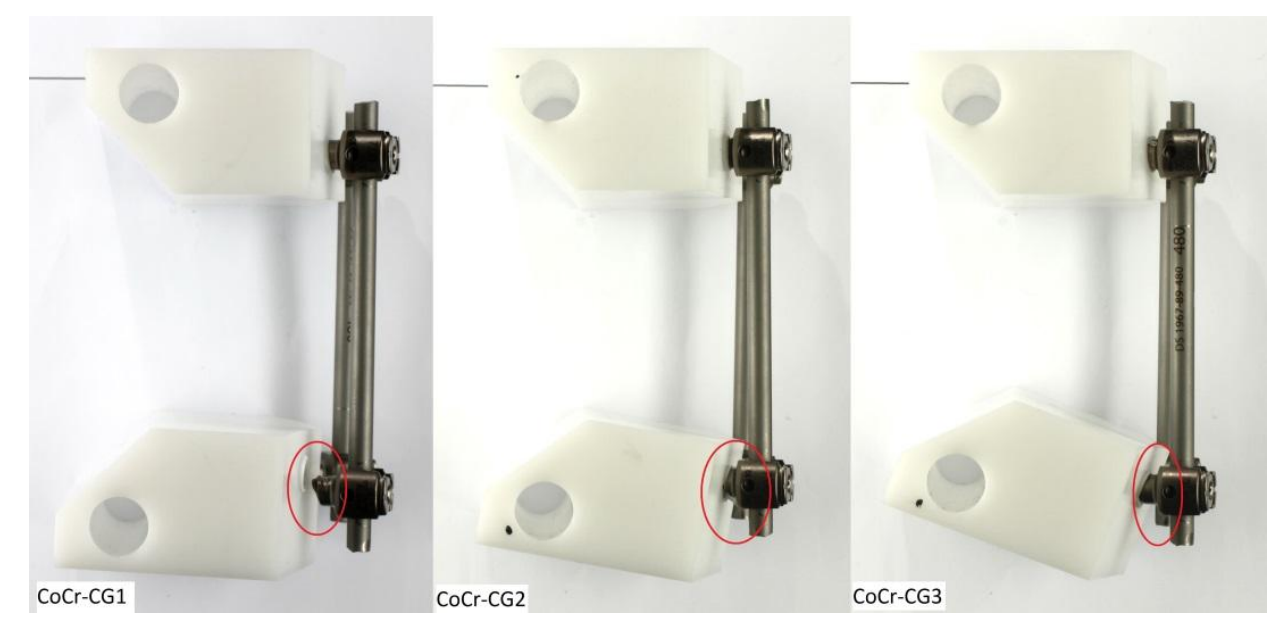

Figure 7. Sites of the titanium screw fracture of $\mathrm{CoCr}$ control group (CoCr-CG) post biomechanical testing.

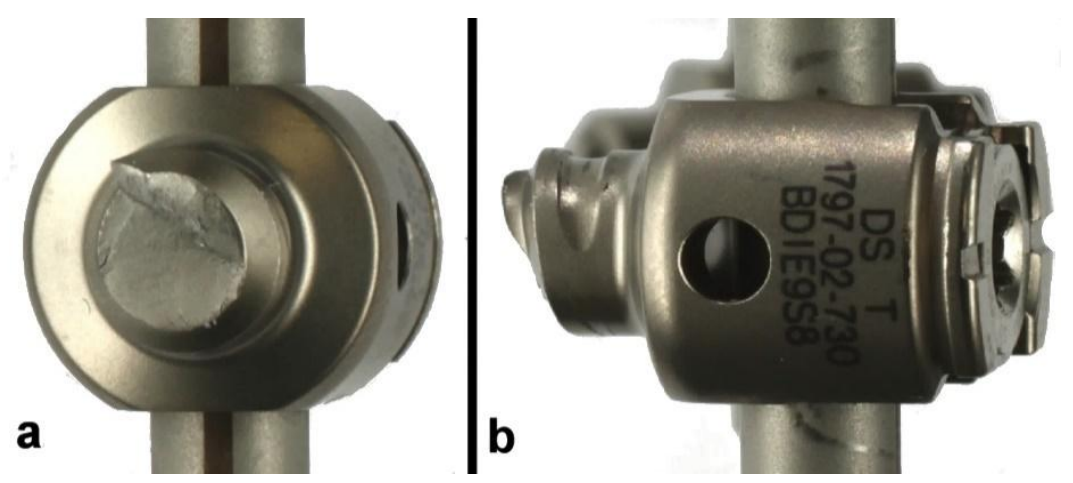

Figure 8. Magnified frontal (a) and lateral (b) views of the titanium screw fracture of one of $\mathrm{CoCr}$ electrocautery group constructs (CoCr-EG 3).

\section{Discussion}

The human body is an intricate biomechanical composite that exerts cyclic loading on spinal instrumentation, which could lead to their failure $[21,30]$. The predominant use of electrocautery in operating-rooms mandates spine surgeons and implant engineers to contemplate the potential negative impact of electrocautery on the long-term integrity of spinal fusion constructs. Thus, addressing differences between the mechanical properties of these materials and studying the thermal effect of electrocautery are essential to predict the in vivo behavior of implants.

The micro-architecture of $\mathrm{Ti}$ and $\mathrm{CoCr}$ materials dictates their biomechanical performance and fatigue life $[21,22,31]$. Instrumentation failure is thought to be caused by recurring loading which generates oscillating stresses that may be well below the yield stress of the material. Unfortunately, 
this process is unnoticeable, either by the patient during daily activities or by the surgeon throughout follow-up visits, until final construct failure develops [21,32,33].

In vivo loading on spinal implants has been previously measured and reported to be $250 \mathrm{~N}$ in the prone position, $400 \mathrm{~N}$ whilst walking, and up to $700 \mathrm{~N}$ during exercise [34-37]. Notably, Ti-EG constructs failed at a maximum load of $250 \mathrm{~N}$. This underlines the potential detrimental impact of electrocautery on the safety of Ti constructs, even within daily physiological loading.

\subsection{Thermal Damage and Notch Sensitivity: A Threat to Ti Biomechanical Integrity}

Previous investigations have emphasized that the load-to-failure is contingent upon a material's resistance to surface alterations. Fatigue fractures almost always nucleate at the exact location of notches or "discontinuity of geometrical structure" on the material's surface $[21,24,31,38,39]$. This is particularly important when the site of the notch corresponds to areas where maximal loading is applied. Very small cracks relative to the dimensions of the micro-structure have been shown to cause failure faster than a long crack $[40,41]$. Therefore, the radius of the notch is, as a geometrical function, important [42]. Jang et al. demonstrated that thermal damage of laser etching on hip implants led to their early fracture [43]. Huber et al. [25] and Konrads et al. [26] reported a decrease in the fatigue life of Ti hip implants due to the thermal damage of electrocautery. In this context, Sonntag et al. [28] further demonstrated that this thermal damage caused a significant alteration of Ti microstructure. Ti6Al4V alloy has a bimodal microstructure consisting of a globular $\alpha$-matrix phase, enveloped by the so-called Widmannstätten structure $(\alpha+\beta)$ [32,44-46]. Thermal energy affects the internal kinetics of theses phases and triggers a cascade of diffusion processes, as well as transforming the dimensions of the $\alpha$ and $\beta$ phases. Alteration of those dimensions correlates with their load-to-failure and susceptibility to internal crack initiation. It could even be regarded as an internal notch [33,47-49].

In the light of these findings, the thermal energy applied on the tested Ti rods and the marks seen on their surface, which may be due to a corrosive attack [27] could set the stage for premature rod failure.

\subsection{Pathogenesis of Ti Rod Fractures at the Rod-Screw Junction}

Among all Ti-CG and one of the Ti-EG specimens, a crack nucleation site was visually detected in the proximity of the locking screw. Tightening of the screw leaves surface marks on the rods and could account for this failure (Figure 9). The presented results echo previously published findings: Lindsey et al. and Ngyuen et al. [21,22] detected an increased trend of CoCr rod failure at the same location of our tested constructs. Yamanaka et al. [40] described the same phenomenon on Ti rods. Dick et al. [31] suggested that surgeons should avoid severe tightening of the screws as this would lead to notch formation on the surface of Ti rods. Hence, a modification of the operating manual might be indicated to avoid severe tightening of the screw. This, however, requires specific testing and is a secondary outcome of this study.

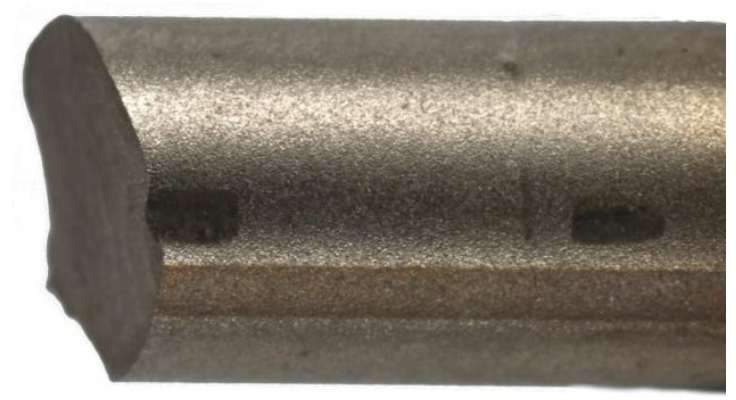

Figure 9. Magnified lateral view of Ti-CG post biomechanical testing: fatigue fracture of the rod at the rod-screw junction, illustrating surface marks of the tightened screws on the rod. 


\subsection{CoCr Versus Ti Rods}

CoCr exhibited a higher fatigue life than $\mathrm{Ti}$, which is in line with previous investigations [23,50,51]. However, we are not aware of previous studies addressing spinal $\mathrm{CoCr}$ susceptibility to thermal modification of electrocautery. Uniquely, our tested constructs were not affected by this thermal modification as the pedicle screws failed. This could be explained by their superior rigidity, corrosion, and wear resistance [52]. This biomechanical superiority is also the reason for their implementation in demanding surgical techniques such as PSO. Paradoxically, in the context of PSO, CoCr constructs were associated with higher rates of RF. This could be due to the notch effect of in situ bending inherent within the PSOs, and the unusually high loading they need to withstand [16]. However, the superior performance of $\mathrm{CoCr}$ comes at the expense of greater stiffness at both ends of the construct, resulting in increased incidence of adjacent segment disease [53-55]. This could be attributed to the fact that Ti-6Al-4V alloy has a much lower Young's modulus ( 112 GPa) when compared to Co-Cr alloys ( 210 GPa) [56,57].

One of the strengths of our study could be its clinical implications. Patient expectations of surgical outcomes have reached unparalleled heights [58]. However, implant-related complications have significant drawbacks on post-operative Health-Related Quality of Life (HRQoL) and were associated with slower rates of improvement $[1,23,59]$. Moreover, the negative economic impact of instrumentation failure and post-operative complications on the health-care system in the context of spine surgery is high $[60,61]$.

This study provides a biomechanical strongpoint by testing constructs under high sinusoidal loading levels ( $n=8$, each $10^{6}$ cycles) in which rod diameter was uniform, which makes the results comparable. Previous biomechanical investigations have tested constructs with different rod diameters and were tested under lower load levels [21,22]. Higher loading levels would give more confidence to the conclusion of long-term fatigue endurance. Intuitively, the longer a spinal implant persists intact in the body, the more cyclic loading it has to withstand. Testing constructs under short- and long-term mechanical loading enabled the conclusion that $\mathrm{CoCr}$ rods, even under long-term cyclic loading $\left(8 \times 10^{6}\right.$ cycles $)$, proved unaffected by thermal damage. Furthermore, constructs were examined according to a standard for spinal instrumentation testing [29]. The application of the ASTM F1717 standard enabled the delineation of electrocautery's impact on the mechanical properties of materials and efficiently eliminated potential confounding factors, such as implant design or donor variability in the context of cadaver studies.

On the other hand, intrinsic to in vitro biomechanical investigations, this study was conducted within a scaffold of limitations and simplifying premises that are important to discuss. First, severity of the electrocautery attack cannot be fully controlled during manual application which could lead to heterogeneity of thermal damage on the tested rods. This could explain why the Ti-EG specimens fractured at different locations. Second, the use of only one cautery mode precludes conclusions on other electrocautery modes. Third, in vivo clinical translation of the findings is impeded by the dry conditions of these experiments which were conducted at room temperature; fatigue life could differ when implants are at body temperature and surrounded by body fluids [39]. Fourth, the application of the ASTM F1717 sinusoidal testing environment represents a "worst case scenario"; constructs alone bore the burden of the axial loading which does not fully represent the in vivo state where the load is also shared by the spine and neighboring soft tissue. However, physiological stresses on implants could be as high as $700 \mathrm{~N}$ which permits us to draw our conclusions, as Ti rods failed in the range of 250 N. Fifth, tested constructs underwent only axial loading, resulting in a bending moment which mimics one modality of human movement, flexion-extension, and does not take into account lateral bending and axial rotation. Finally, we did not perform a power analysis prior to conducting this study to determine the minimum sample size required for the CI of $95 \%$. Also, the wide $\mathrm{CI}$ is attributed to the small sample size. However, this limitation means that the impact of electrocautery could have been underestimated in our results. Subsequently, a larger sample size would enable calculation of a statistically significant hazard ratio to quantify the negative impact of thermal damage on the 
fatigue life of Ti rods. Future biomechanical studies with a larger sample size are merited to analyze different settings of coagulation and cutting modes, and to assess loadings exerted by bending and axial rotation of vertebrae. Randomized controlled studies are required to determine the absolute effect of electrocautery on spinal implants. Nevertheless, our findings disentangle a potential culprit underlying post-operative Ti rod fracture.

\section{Conclusions}

This biomechanical study showed that the impact of electrocautery on Ti rods could have significant clinical and biomechanical repercussions for patient safety and satisfaction, surgical training, and implant design. Ti rods exhibited decreased fatigue life and failed at the site of electrocautery application. Spine surgeons should exercise caution in the vicinity of spinal implants, especially during revisions. Similarly, it is also reasonable for manufacturers to devise strategies against thermal damage and explore methods to increase the long-term structural integrity of Ti rods.

Author Contributions: H.A: Investigation, formal analysis, writing the original manuscript, review and editing. R.S. and W.P.: Conceptualization, methodology and resource acquisition, review and editing. T.B.: Statistical analysis support. J.-P.K. and M.A.: Project administration, funding acquisition, resources and supervision. All authors critically reviewed the manuscript.

Funding: This research was funded by Deutsche Arthrose-Hilfe. Grant number P399-A326 and the APC was partially funded by Deutsche Forschungsgemeinschaft within the funding program Open Access Publishing, by the Baden-Württemberg Ministry of Science, Research and the Arts and by Ruprecht-Karls-Universität Heidelberg.

Conflicts of Interest: The authors declare no conflicts of interest. The sponsors had no role in the design, execution, interpretation, or writing of the study.

\section{References}

1. Soroceanu, A.; Diebo, B.G.; Burton, D.; Smith, J.S.; Deviren, V.; Shaffrey, C.; Kim, H.J.; Mundis, G.; Ames, C.; Errico, T. Radiographical and implant-related complications in adult spinal deformity surgery: Incidence, patient risk factors, and impact on health-related quality of life. Spine 2015, 40, 1414-1421. [CrossRef]

2. Sciubba, D.M.; Yurter, A.; Smith, J.S.; Kelly, M.P.; Scheer, J.K.; Goodwin, C.R.; Lafage, V.; Hart, R.A.; Bess, S.; Kebaish, K.; et al. A Comprehensive Review of Complication Rates after Surgery for Adult Deformity: A Reference for Informed Consent. Spine Deform. 2015, 3, 575-594. [CrossRef]

3. Hibbs, R.A.; Peltier, L.F. A report of fifty-nine cases of scoliosis treated by the fusion operation. Clin. Orthop. Relat. Res. 1988, 229, 4-19.

4. Heary, R.F.; Madhavan, K. The History of Spinal Deformity. Neurosurgery 2008, 63, A5-A15. [CrossRef]

5. Albee, F.H. The classic: Transplantation of a portion of the tibia into the spine for Pott's disease: A preliminary report. Clin. Orthop. Relat. Res. 2007, 460, 14-16. [CrossRef]

6. King, D. Internal fixation for lumbosacral fusion. JBJS 1948, 30, 560-578. [CrossRef]

7. Lange, F. Support for the spondylitic spine by means of buried steel bars, attached to the vertebrae. JBJS 1910, 2, 344-361.

8. Harrington, P.R. Treatment of scoliosis: Correction and internal fixation by spine instrumentation. JBJS 1962, 44, 591-634. [CrossRef]

9. Cotrel, Y.; Dubousset, J. A new technic for segmental spinal osteosynthesis using the posterior approach. Revue de Chirurgie Orthopédique et Réparatrice de L'appareil Moteur 1984, 70, 489-494. [CrossRef]

10. Kaur, M.; Singh, K. Review on titanium and titanium based alloys as biomaterials for orthopaedic applications. Mater. Sci. Eng. C 2019, 102, 844-862. [CrossRef]

11. Liu, X.; Chu, P.K.; Ding, C. Surface modification of titanium, titanium alloys, and related materials for biomedical applications. Mater. Sci. Eng. R Rep. 2004, 47, 49-121. [CrossRef]

12. Liu, W.; Liu, S.; Wang, L. Surface Modification of Biomedical Titanium Alloy: Micromorphology, Microstructure Evolution and Biomedical Applications. Coatings 2019, 9, 249. [CrossRef]

13. Kyzioł, K.; Kaczmarek, Ł.; Brzezinka, G.; Kyzioł, A. Structure, characterization and cytotoxicity study on plasma surface modified Ti-6Al-4V and $\gamma$-TiAl alloys. Chem. Eng. J. 2014, 240, 516-526. [CrossRef] 
14. Smith, J.S.; Sansur, C.A.; Donaldson, W.F., 3rd; Perra, J.H.; Mudiyam, R.; Choma, T.J.; Zeller, R.D.; Knapp, D.R., Jr.; Noordeen, H.H.; Berven, S.H.; et al. Short-term morbidity and mortality associated with correction of thoracolumbar fixed sagittal plane deformity: A report from the Scoliosis Research Society Morbidity and Mortality Committee. Spine 2011, 36, 958-964. [CrossRef]

15. Scheer, J.K.; Tang, J.A.; Deviren, V.; Acosta, F.; Buckley, J.M.; Pekmezci, M.; McClellan, R.T.; Ames, C.P. Biomechanical analysis of cervicothoracic junction osteotomy in cadaveric model of ankylosing spondylitis: Effect of rod material and diameter. J. Neurosurg. Spine 2011, 14, 330-335. [CrossRef]

16. Smith, J.S.; Klineberg, E.; Lafage, V.; Shaffrey, C.I.; Schwab, F.; Lafage, R.; Hostin, R.; Mundis, G.M.; Errico, T.J.; Kim, H.J.; et al. Prospective multicenter assessment of perioperative and minimum 2-year postoperative complication rates associated with adult spinal deformity surgery. J. Neurosurg. Spine 2016, 25, 1-14. [CrossRef]

17. Bridwell, K.H.; Baldus, C.; Berven, S.; Edwards, C., 2nd; Glassman, S.; Hamill, C.; Horton, W.; Lenke, L.G.; Ondra, S.; Schwab, F.; et al. Changes in radiographic and clinical outcomes with primary treatment adult spinal deformity surgeries from two years to three- to five-years follow-up. Spine 2010, 35, 1849-1854. [CrossRef]

18. Cho, S.K.; Bridwell, K.H.; Lenke, L.G.; Yi, J.S.; Pahys, J.M.; Zebala, L.P.; Kang, M.M.; Cho, W.; Baldus, C.R. Major complications in revision adult deformity surgery: Risk factors and clinical outcomes with 2- to 7-year follow-up. Spine 2012, 37, 489-500. [CrossRef]

19. Bagchi, K.; Mohaideen, A.; Thomson, J.D.; Foley, L.C. Hardware complications in scoliosis surgery. Pediatr. Radiol. 2002, 32, 465-475. [CrossRef]

20. Bago, J.; Ramirez, M.; Pellise, F.; Villanueva, C. Survivorship analysis of Cotrel-Dubousset instrumentation in idiopathic scoliosis. Eur. Spine J. 2003, 12, 435-439. [CrossRef]

21. Lindsey, C.; Deviren, V.; Xu, Z.; Yeh, R.F.; Puttlitz, C.M. The effects of rod contouring on spinal construct fatigue strength. Spine 2006, 31, 1680-1687. [CrossRef]

22. Nguyen, T.Q.; Buckley, J.M.; Ames, C.; Deviren, V. The fatigue life of contoured cobalt chrome posterior spinal fusion rods. Proc. Inst. Mech. Eng. Part H J. Eng. Med. 2011, 225, 194-198. [CrossRef]

23. Smith, J.S.; Shaffrey, C.I.; Ames, C.P.; Demakakos, J.; Fu, K.M.; Keshavarzi, S.; Li, C.M.; Deviren, V.; Schwab, F.J.; Lafage, V.; et al. Assessment of symptomatic rod fracture after posterior instrumented fusion for adult spinal deformity. Neurosurgery 2012, 71, 862-867. [CrossRef]

24. Tang, J.A.; Leasure, J.M.; Smith, J.S.; Buckley, J.M.; Kondrashov, D.; Ames, C.P. Effect of severity of rod contour on posterior rod failure in the setting of lumbar pedicle subtraction osteotomy (PSO): A biomechanical study. Neurosurgery 2013, 72, 276-282. [CrossRef]

25. Huber, G.; Weik, T.; Morlock, M.M. Schädigung eines Hüftendoprothesenschafts durch Einsatz eines Hochfrequenzmessers. Der Orthopäde 2009, 38, 622-625. [CrossRef]

26. Konrads, C.; Wente, M.N.; Plitz, W.; Rudert, M.; Hoberg, M. Implantatschädigung durch Einsatz eines Hochfrequenzmessers. Der Orthopäde 2014, 43, 1106-1111. [CrossRef]

27. Yuan, N.; Park, S.H.; Luck, J.V.; Campbell, P.A. Revisiting the concept of inflammatory cell-induced corrosion. J. Biomed. Mater. Res. Part B Appl. Biomater. 2017, 106B, 1148-1155. [CrossRef]

28. Sonntag, R.G.J.; Pulvermacher, S.; Mueller, U.; Eckert, J.; Braun, S.; Reichkendler, M.; Kretzer, J.P. Electrocautery damage can reduce implant fatigue strength: Cases and in vitro investigation. J. Bone Jt. Surg. 2019, 101, 868-878. [CrossRef]

29. ASTM-International. Standard Test Methods for Spinal Implant Constructs in a Vertebrectomy Model. Available online: https://www.astm.org/Standards/F1717.htm (accessed on 20 May 2019).

30. Ashman, R. Mechanical testing of spinal implants. Semin. Spine Surg. 1993, 5, 73-80.

31. Dick, J.; Bourgeault, C. Notch sensitivity of titanium alloy, commercially pure titanium, and stainless steel spinal implants. Spine 2001, 26, 1668-1672. [CrossRef]

32. Wang, S.; Wei, M. Tensile properties of gas tungsten arc weldments in commercially pure titanium, Ti-6Al-4V and Ti-15V-3Al-3Sn-3Cr alloys at different strain rates. Sci. Technol. Weld. Join. 2004, 9, 415-422. [CrossRef]

33. Lütjering, G. Influence of processing on microstructure and mechanical properties of $(\alpha+\beta)$ titanium alloys. Mater. Sci. Eng. A 1998, 243, 32-45. [CrossRef]

34. Rohlmann, A.; Graichen, F.; Bender, A.; Kayser, R.; Bergmann, G. Loads on a telemeterized vertebral body replacement measured in three patients within the first postoperative month. Clin. Biomech. 2008, 23, 147-158. [CrossRef] 
35. Rohlmann, A.; Bergmann, G.; Graichen, F. Loads on an internal spinal fixation device during walking. J. Biomech. 1997, 30, 41-47. [CrossRef]

36. Rohlmann, A.; Claes, L.; Bergmann, G.; Graichen, F.; Neef, P.; Wilke, H.-J. Comparison of intradiscal pressures and spinal fixator loads for different body positions and exercises. Ergonomics 2001, 44, 781-794. [CrossRef]

37. D'Lima, D.D.; Fregly, B.J.; Colwell, C.W. Implantable sensor technology: Measuring bone and joint biomechanics of daily life in vivo. Arthritis Res. Ther. 2013, 15, 203. [CrossRef]

38. Tang, J.A. Comparison of a novel pedicle subtraction osteotomy model using the traditional American Society of Testing and Materials standard for spinal biomechanics fatigue testing [RETRACTED]. J. Neurosurg. Spine 2012. [CrossRef]

39. Chen, P.Q.; Lin, S.J.; Wu, S.S.; So, H. Mechanical performance of the new posterior spinal implant: Effect of materials, connecting plate, and pedicle screw design. Spine 2003, 28, 881-886. [CrossRef]

40. Yamanaka, K.; Mori, M.; Yamazaki, K.; Kumagai, R.; Doita, M.; Chiba, A. Analysis of the Fracture Mechanism of Ti-6Al-4V Alloy Rods That Failed Clinically After Spinal Instrumentation Surgery. Spine 2015, 40, E767-E773. [CrossRef]

41. Ravichandran, K. Three-dimensional crack-shape effects during the growth of small surface fatigue cracks in a titanium-base alloy. Fatigue Fract. Eng. Mater. Struct. 1997, 20, 1423-1442. [CrossRef]

42. Cook, R.D.; Young, W.C. Advanced Mechanics of Materials; Prentice Hall: Upper Saddle River, NJ, USA, 1999.

43. Jang, B.; Kanawati, A.; Brazil, D.; Bruce, W. Laser etching causing fatigue fracture at the neck-shoulder junction of an uncemented femoral stem: A case report. J. Orthop. 2013, 10, 95-98. [CrossRef]

44. Malinov, S.; Sha, W. Application of artificial neural networks for modelling correlations in titanium alloys. Mater. Sci. Eng. A 2004, 365, 202-211. [CrossRef]

45. Balasubramanian, M.; Jayabalan, V.; Balasubramanian, V. Effect of microstructure on impact toughness of pulsed current GTA welded $\alpha-\beta$ titanium alloy. Mater. Lett. 2008, 62, 1102-1106. [CrossRef]

46. Pederson, R.; Babushkin, O.; Skystedt, F.; Warren, R. Use of high temperature X-ray diffractometry to study phase transitions and thermal expansion properties in Ti-6Al-4V. Mater. Sci. Technol. 2003, 19, 1533-1538. [CrossRef]

47. Oguma, H.; Nakamura, T. The effect of microstructure on very high cycle fatigue properties in Ti-6Al-4V. Scr. Mater. 2010, 63, 32-34. [CrossRef]

48. Everaerts, J.; Verlinden, B.; Wevers, M. The influence of the alpha grain size on internal fatigue crack initiation in drawn Ti-6Al-4V wires. Procedia Struct. Integr. 2016, 2, 1055-1062. [CrossRef]

49. Gil, F.; Rodriguez, D.; Planell, J. Grain growth kinetics of pure titanium. Scr. Metall. Mater. $1995,33$. [CrossRef]

50. Shinohara, K.; Takigawa, T.; Tanaka, M.; Sugimoto, Y.; Arataki, S.; Yamane, K.; Watanabe, N.; Ozaki, T.; Sarai, T. Implant Failure of Titanium Versus Cobalt-Chromium Growing Rods in Early-onset Scoliosis. Spine 2016, 41, 502-507. [CrossRef]

51. Doulgeris, J.J.; Aghayev, K.; Gonzalez-Blohm, S.A.; Del Valle, M.; Waddell, J.; Lee, W.E.; Vrionis, F.D. Comparative analysis of posterior fusion constructs as treatments for middle and posterior column injuries: An in vitro biomechanical investigation. Clin. Biomech. 2013, 28, 483-489. [CrossRef]

52. Wojnar, L.; Dabbrowski, J.R.; Oksiuta, Z. Porosity structure and mechanical properties of vitalium-type alloy for implants. Mater. Charact. 2001, 46, 221-225. [CrossRef]

53. Serhan, H.; Mhatre, D.; Newton, P.; Giorgio, P.; Sturm, P. Would CoCr rods provide better correctional forces than stainless steel or titanium for rigid scoliosis curves? J. Spinal Disord. Tech. 2013, 26, E70-E74. [CrossRef]

54. Lamerain, M.; Bachy, M.; Delpont, M.; Kabbaj, R.; Mary, P.; Vialle, R. CoCr rods provide better frontal correction of adolescent idiopathic scoliosis treated by all-pedicle screw fixation. Eur. Spine J. Off. Publ. Eur. Spine Soc. Eur. Spinal Deform. Soc. Eur. Sect. Cerv. Spine Res. Soc. 2014, 23, 1190-1196. [CrossRef]

55. Han, S.; Hyun, S.J.; Kim, K.J.; Jahng, T.A.; Kim, H.J. Comparative Study Between Cobalt Chrome and Titanium Alloy Rods for Multilevel Spinal Fusion: Proximal Junctional Kyphosis More Frequently Occurred in Patients Having Cobalt Chrome Rods. World Neurosurg. 2017, 103, 404-409. [CrossRef]

56. Geetha, M.; Singh, A.K.; Asokamani, R.; Gogia, A.K. Ti based biomaterials, the ultimate choice for orthopaedic implants-A review. Prog. Mater. Sci. 2009, 54, 397-425. [CrossRef]

57. Niinomi, M.; Liu, Y.; Nakai, M.; Liu, H.; Li, H. Biomedical titanium alloys with Young's moduli close to that of cortical bone. Regen. Biomater. 2016, 3, 173-185. [CrossRef] 
58. Saban, K.L.; Penckofer, S.M. Patient expectations of quality of life following lumbar spinal surgery. J. Neurosci. Nurs. 2007, 39, 180-189. [CrossRef]

59. Cho, K.-J.; Suk, S.-I.; Park, S.-R.; Kim, J.-H.; Kim, S.-S.; Choi, W.-K.; Lee, K.-Y.; Lee, S.-R. Complications in Posterior Fusion and Instrumentation for Degenerative Lumbar Scoliosis. Spine 2007, 32, 2232-2237. [CrossRef]

60. McCarthy, I.; Hostin, R.; O’Brien, M.; Saigal, R.; Ames, C.P. Health Economic Analysis of Adult Deformity Surgery. Neurosurg. Clin. N. Am. 2013, 24, 293-304. [CrossRef]

61. Yeramaneni, S.; Robinson, C.; Hostin, R. Impact of spine surgery complications on costs associated with management of adult spinal deformity. Curr. Rev. Musculoskelet. Med. 2016, 9, 327-332. [CrossRef]

(C) 2019 by the authors. Licensee MDPI, Basel, Switzerland. This article is an open access article distributed under the terms and conditions of the Creative Commons Attribution (CC BY) license (http://creativecommons.org/licenses/by/4.0/). 